\title{
Refúgio de vida silvestre, ecoturismo e implicações jurídicas: experiência na Região Metropolitana de Belém (PA)
}

\author{
Wildlife refuge, ecotourism and juridical implications: \\ experience in the Belem's Metropolitan Region (PA, Brazil)
}

Rosa de Figueiredo Lavor, Luiz Antonio Gomes de Souza Monteiro de Brito, Fernando Gomes Favacho, Paulo Moreira Pinto

RESUMO: $O$ artigo faz referência às implicações jurídicas promovidas pela criação de Unidade de Conservação, precisamente de um Refúgio de Vida Silvestre localizado em área urbana da Região Metropolitana de Belém, no estado do Pará, e a inserção de atividades de ecoturismo. O contexto jurídico implicado na questão refere-se ao que está consagrado pelo denominado Sistema de Unidades de Conservação da Natureza que determina as categorias de manejo e o seu uso. Nesse caso, a categoria Unidade de Proteção Integral não permite o uso direto dos recursos naturais por populações tradicionais ou não, que residem no interior desses espaços territoriais legalmente protegidos. Nessa conjuntura, a sustentabilidade dos recursos biossocioculturais é planejada a partir da adoção do ecoturismo enquanto componente estratégico da administração e da gestão pública e, para a conservação ambiental. Entretanto, o segmento de mercado do ecoturismo, enquanto atividade econômica, pode reproduzir conflitos históricos e antagônicos vivenciados pelas populações amazônicas como, por exemplo, o desenvolvimento marginal e excludente das comunidades locais. Tal fato propicia entraves de ordens as mais diversas ao planejamento, administração e gestão das instituições públicas destinadas a administrar essas áreas. Do ponto de vista jurídico o arcabouço legal tem se pautado pelo imobilismo com relação às problemáticas advindas pela presença humana nesses espaços. A execução do estudo iniciou-se pela pesquisa bibliográfica e documental, utilizando-se também a observação direta por intermédio da participação em fóruns de debates organizados por instâncias de governança capitaneadas pelo poder público. Como resultado tem-se uma análise crítica preliminar, haja vista a criação e a organização recentes dessa Unidade de Conservação, pautada pela profusão de normas do Direito Ambiental que prejudicam resoluções de caráter mais flexíveis. Dessa maneira, estudos são necessários para aprofundar o tema com vistas às soluções que sejam benéficas para a manutenção da biossociodiversidade, principalmente em se tratando de áreas e populações amazônicas.

PALAVRAS-CHAVE: Refúgio de Vida Silvestre; Ecoturismo; Gestão; Área Urbana; Análise Jurídica.

Sociedade Brasileira de Ecoturismo. Rua Dona Avelina, 225, Vila Mariana, São Paulo, SP, Brasil 178 E-mail: zneiman@gmail.com; Tel. (55-11) 99195-7685. 
ABSTRACT: This article refers to the possible juridical implications promoted by the creation of a Conservation Unit, precisely a Wildlife Refuge, located in a urban area of the Metropolitan Region of Belém, in the state of Pará (Brazil); moreover, the insertion of Ecotourism activities. The juridical context implied in the question refers to what is declared by the denominated National System of Conservation Unities that determines the categories of handling and their use. In this case, the category of Integral Protection Unit does not allow the direct use of natural resources by traditional or nontraditional populations residing within these legally protected territorial spaces. At the present juncture, the sustainability of the biosocioculturals resources is planned based on the adoption of ecotourism so far as strategic component of administration and public governance, and for environmental conservation. However, the ecotourism market segment while economic activity, can reproduce historical and antagonistic conflicts experienced by Amazonian populations, as for instance the marginal and exclusionary development of the local communities. This fact provides obstacles of several orders to the planning, administration and management of the public institutions destined to manage these areas. From the juridical point of view, the legal framework has been based on immobility in relation to the problems caused by the human presence in these spaces. For the execution of the present study, we started with bibliographical and documentary research, also using direct observation through participation in discussion forums organized by instances of governance captained by the government. As a result, there is a preliminary critical analysis, due to the recent creation and organization of this Conservation Unit, based on the profusion of Environmental Law norms that hamper resolutions that are more flexible. Given these points, studies are needed to deepen the issue in order to emerge solutions that could be beneficial for the maintenance of biosociodiversity, mainly in the case of Amazonian areas and populations.

KEYWORDS: Wildlife Refuge; Ecotourism; Management; Urban Area; Juridical Analysis.

\section{Introdução}

O artigo propõe como problemática central a criação de uma Unidade de Conservação (UC), a adoção de atividades do segmento de mercado do ecoturismo e as implicações jurídicas advindas do planejamento e da gestão pública de UC. A temática em questão objetiva fazer uma análise jurídica sobre a aplicabilidade dos instrumentos de administração e gestão da UC Refúgio de Vida Silvestre Metrópole da Amazônia (REVISMA), criada em 2010, na Região Metropolitana de Belém (RMB), pelo Governo do Estado do Pará. O principal objetivo é verificar a plataforma de administração e gestão da Unidade de Proteção Integral (UPI) REVISMA, traçando uma análise jurídica fundamentada nos instrumentos legais que dispõem a Lei n. 9.985, de 18 de julho de 2000, que institui o Sistema Nacional de Unidades de Conservação da Natureza (SNUC). 
A UC REVISMA abrange quatro municípios da RMB, a saber: Ananindeua, Benevides, Marituba e Santa Isabel. Sendo área detentora de diversidade socioambiental enorme, considerada ímpar na região, onde o solo é recortado por rios, lagos, furos e igarapés, coberto por vegetação característica das áreas de várzea, terra firme e igapós, que servem de refúgio para espécies diversas da fauna e flora silvestre. Ocorre que toda essa riqueza natural, conservada ao longo do tempo, é habitada por comunidades locais há muitos anos, as quais têm esses recursos naturais como importante meio de sobrevivência, com base na prática de atividades extrativistas, tais como: coletas de frutos, principalmente o açaí (Euterpe oleracea); a pesca e a extração do látex da seringueira (Hevea brasiliensis). Em conjunto, essas práticas compõem o principal modo de subsistência.

O contexto que envolve a UPI REVISMA, localizada em área urbana, como já mencionado, é território habitado por comunidades locais de expressão cultural relevante para o patrimônio histórico-ambiental da região. Tal fato eleva o grau de complexidade das relações sociais, devido ao REVISMA ser uma categoria de UPI que restringe - ao máximo possível - 0 acesso de pessoas na área. Por causa desse cenário ambiental rico, desafios prementes são impostos à administração e a gestão do REVISMA; por um lado, existe a restrição legal do uso do espaço e, por outro, a garantia dos direitos adquiridos pelas comunidades locais.

Portanto, o artigo em questão tende a contribuir para o debate acerca das estratégias aplicadas pela administração e gestão do REVISMA, no que concerne aos instrumentos jurídicos estabelecidos na legislação vigente. $O$ desenvolvimento de atividades de ecoturismo tem sido outro importante fator que implica em questões jurídicas e o modus vivendi dessas populações. É sem dúvida uma experiência bastante motivadora para os estudos do Turismo e do Direito Ambiental por buscar proteger territórios, ainda conservados, às proximidades de grandes centros urbanos.

\section{Material e Métodos}

\section{Procedimentos Metodológicos}

A situação problema deste estudo procura identificar quais as estratégias utilizadas para possibilitar a implantação da UPI Refúgio de Vida Silvestre (REVIS) localizada em área urbana. Para tanto, realizou-se pesquisa bibliográfica em livros, artigos, teses e outros, seguindo o que é recomendado por Severino (2007) sobre a necessidade de investigar as análises e contribuições de outros estudos sobre o tema que se quer pesquisar.

Fez-se também pesquisa documental, a qual vem a ser o cerne do estudo proposto, principalmente, nos documentos oficiais, ou seja, nos legalmente instituídos pelo Estado brasileiro. Nesse caso, levando-se em consideração o que também foi indicado por Oliveira (2002) e Severino (2007) em dar tratamento analítico ao material bruto que conduzirá a investigação e as análises decorrentes. 
A abordagem qualitativa foi utilizada em conformidade com Cesar (2006, p. 2) por tratar-se de estudo que envolve "[...] a compreensão da vida humana em grupos". Corroborando com Oliveira (2002) sobre a compreensão e a classificação de "[...] processos dinâmicos experimentados por grupos sociais". Isto porque se propôs a observar os procedimentos de gestão e os instrumentos aplicados pela administração da UPI REVISMA.

A pesquisa de campo foi importante para identificar e examinar as contradições e as dinâmicas biossocioculturais como apontado por Neto (2002, p. 54) quando afirma que o lugar primordial da pesquisa social "[...] é ocupado pelas pessoas e grupos convivendo numa dinâmica de interação social'. Para Oliveira (2002, p. 124) trata-se da "[...] observação dos fatos tal como ocorrem espontaneamente, na coleta de dados e no registro de variáveis presumivelmente para posteriores análises". Desta feita, a participação em reunião do Conselho Deliberativo do REVISMA, que teve como pauta a aprovação de instrumentos para a gestão do Plano de Manejo, foi de fundamental importância.

Além disso, o survey conduzido junto aos representantes do Conselho Deliberativo do REVISMA foi realizado como proposto por Babbie (1999) acerca de suas três finalidades: descrição, explicação e exploração. Neste sentido, a visita e a participação em reunião de planejamento das ações em uma das comunidades quilombolas do REVISMA possibilitou o registro das três finalidades descritas.

Foram realizadas coletas de informações mediante entrevistas nãodiretivas que, de acordo com Severino (2007, p. 125), vem a ser a coleta de "[...] informações dos sujeitos a partir do seu discurso livre. O entrevistador mantém-se em escuta atenta, registrando todas as informações e só intervindo discretamente para, eventualmente, estimular o depoente". Assim, foram entrevistados o Presidente do Conselho e Diretor do REVISMA, a representante e coordenadora de elaboração do Plano de Manejo junto à empresa licitante, bem como o representante do Batalhão de Polícia Ambiental responsável pela segurança do REVISMA.

Ressalte-se que a participação, na condição de ouvinte, na reunião do Conselho Deliberativo e Gestor do REVISMA foi realizada em maio de 2017, para aprovação do Plano de Manejo. O convite para participar de reunião na comunidade quilombola ocorreu também no mesmo mês de maio de 2017. Tal reunião teve como objetivo planejar as ações para o desenvolvimento local (turismo, agricultura etc.).

\section{Caracterização, Localização e Aspectos Naturais e Socioambientais do REVISMA}

O REVISMA é uma Unidade de Proteção Integral Estadual, vinculada ao Instituto de Desenvolvimento Florestal e da Biodiversidade do Estado do Pará (IDEFLOR-Bio), criada pelo Decreto n. 2.211, de 20 de março de 2010 (PARÁ, 2017).

Encontra-se localizado numa área de $6.367,27$ hectares, que representa $6,3 \%$ da área total dos quatro municípios da RMB: Ananindeua, 
Benevides, Marituba e Santa Isabel do Pará. Área na qual se localizava, anteriormente, a antiga fábrica da Pirelli. O REVISMA fica distante a $23 \mathrm{Km}$ do município de Belém, com acesso realizado por via terrestre a partir do $\mathrm{Km}$ 14 da BR-316, seguindo por mais $4 \mathrm{Km}$ pela chamada "Estrada da Pirelli" (Figura1).

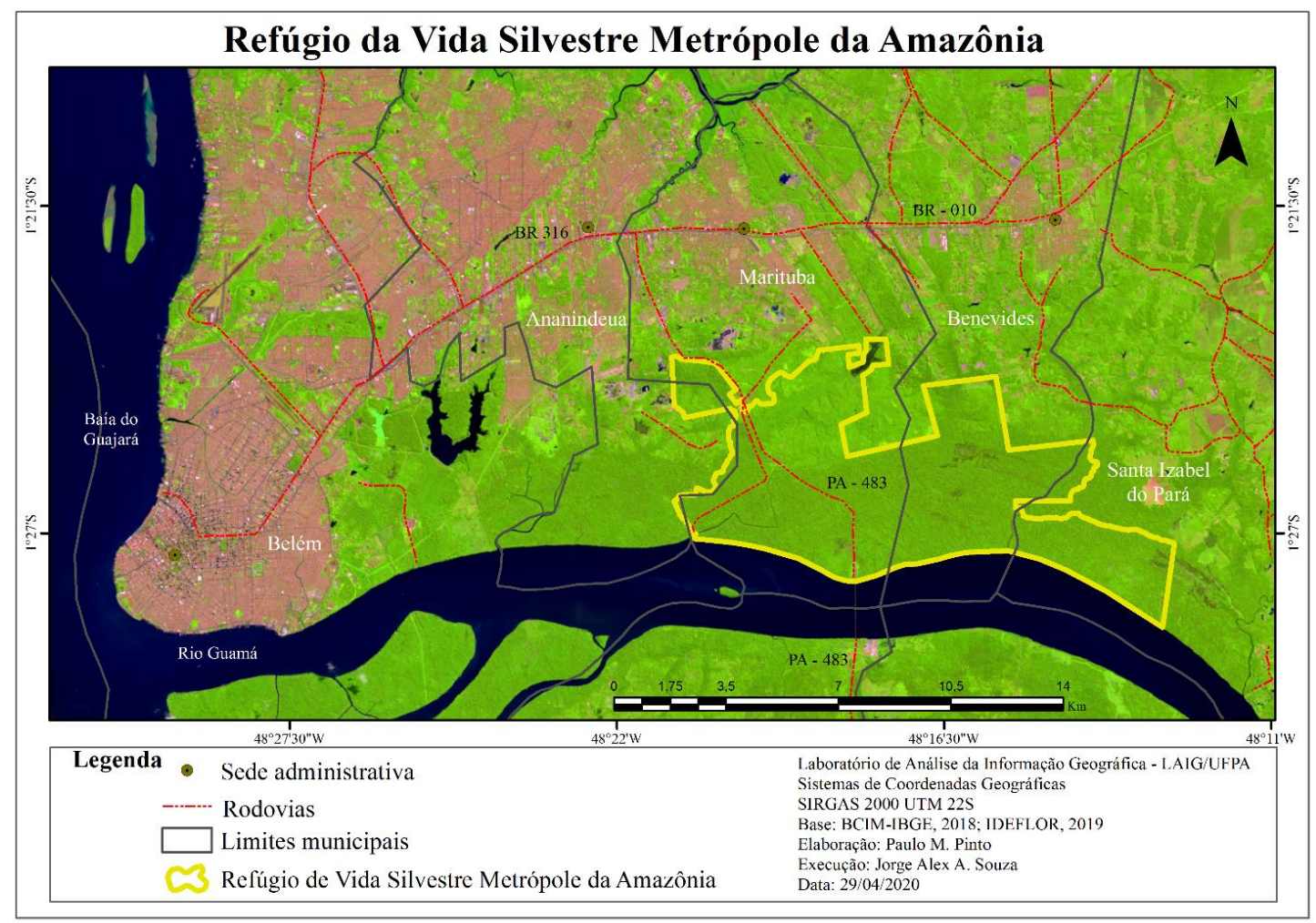

Figura 1: Mapa de localização do REVISMA

Figure 1: Map of location of REVISMA

Fonte: Pinto e Souza (2020).

Source: Pinto and Souza (2020).

O REVISMA destaca-se dentre as demais UC existentes na RMB por dois aspectos bastante relevantes: por ser uma UPI; ser a maior área protegida dentre as demais UCs. Em conformidade com estudos de Almeida (2013, p. 56):

O Refúgio de Vida Silvestre Metrópole da Amazônia, é o maior fragmento de floresta da Região Metropolitana de Belém, [...] e tem em sua área geográfica próxima, outras áreas protegidas [...]. Nessa região, entre outros fragmentos de floresta, estão: [...] Parque Estadual do Utinga; APA da Região Metropolitana de Belém (Estadual); APA da Ilha do Combú (Estadual); Terra Quilombola do Abacatal (estadual). 
Consideram-se essas especificidades do REVISMA como de extrema importância para a conservação da natureza, principalmente das espécies da fauna e da flora da Região Amazônica, incluindo as espécies migratórias que usam essa área para reprodução e refúgio.

O REVISMA apresenta características próprias da Região Amazônica, pois reúne em sua extensão uma pequena amostra da exuberância dos recursos naturais da Amazônia. Nas considerações do IDEFLOR-Bio (2018, p. 9) citando o art. 13 do SNUC, a UC tem como principal objetivo "[...] proteger ambientes naturais para que sejam asseguradas condições de existência ou reprodução de espécies ou comunidades da flora local e da fauna residente ou migratória". Sua missão é a de contribuir para a conservação de $31 \%$ restante de florestas primárias da RMB, considerada de grande relevância para o Estado do Pará.

Em conformidade com estudos do IDEFLOR-Bio, o REVISMA é considerado de extrema importância para a conservação ambiental por resguardar os ecossistemas aquáticos $(6,5 \%)$, de terra firme $(25,7 \%)$ e de várzea $(67,8 \%)$. Seu solo é banhado pelo rio Guamá e recortado por furos e igarapés (Figura 2). A cobertura vegetal contempla uma área de floresta preservada onde foram identificadas diversas espécies vegetais ameaçados de extinção, como angelim (Hymenolobium petraeum), acapu (Vouacapoua americana), cedro (Cedrela fissilis), castanheira do Pará (Bertholletia excelsa) e a ucuúba branca (Virola surinamensis); além das áreas de capoeiras, pastagens abandonadas, plantações de seringueira (Hevea brasiliensis) e rucum (Bixa orellana). A fauna é bastante diversificada, apresentando grande quantidade de macacos-de-cheiro (Saimiri sciureus), bem como pacas (Cuniculus paca), veados-mateiros (Mazama americana), tatus (Priodontes massimos) e capivaras (Hidrochoerus hydrochaeris). Existem ainda espécies variadas de anfíbios e répteis.

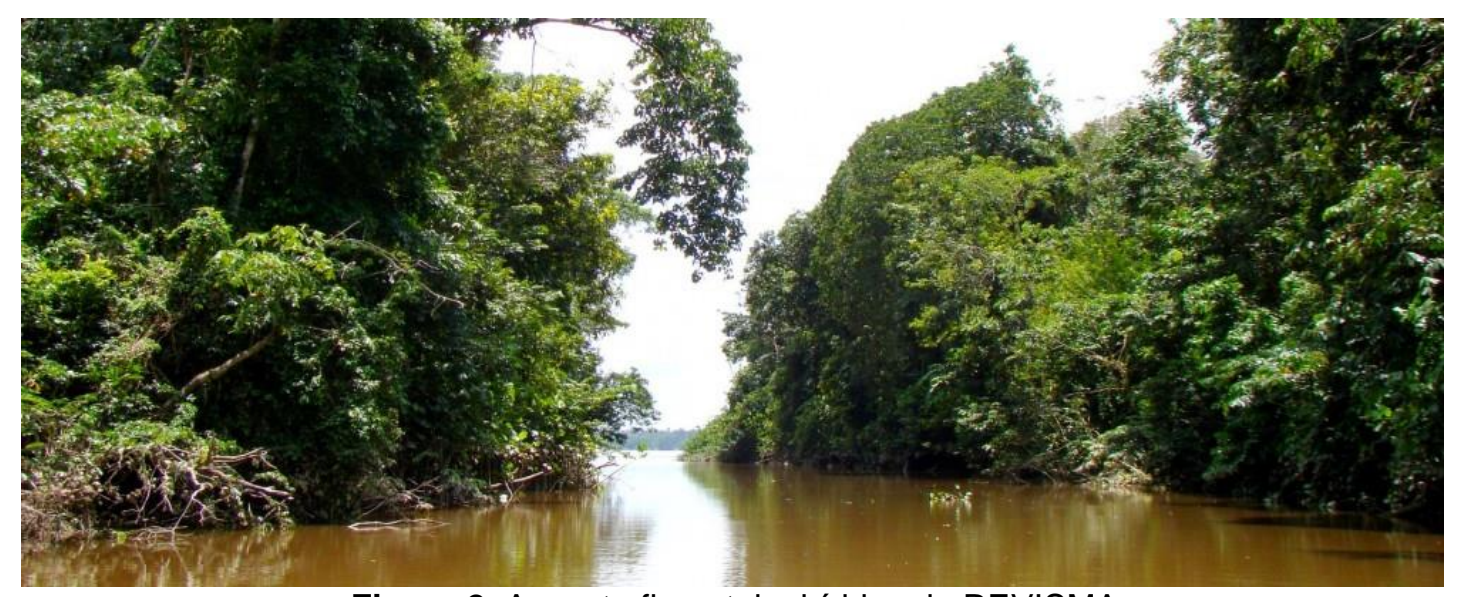

Figura 2: Aspecto florestal e hídrico do REVISMA

Figure 2: Forestry and water aspect of REVISMA

Fonte: Ideflor-Bio (2016).

Source: Ideflor-Bio (2016).

A conservação dos recursos naturais e histórico-culturais do REVISMA é extremamente importante para o desenvolvimento humano. 
Haja vista que além de compor um cenário bastante atrativo para a realização de atividades de pesquisa, lazer e contemplação da natureza, também podem trazer consequências positivas para a dinamização da geração de trabalho e renda. Leff (2001, p. 66) ao cogitar sobre a internalização das condições ecológicas sugere a construção de "[...] um novo paradigma produtivo que integre a natureza e a cultura como forças produtivas". Diniz (2017, p. 253) ao analisar a relação entre desmatamento e pobreza na Amazônia, enfatiza que:

O aumento das oportunidades de ocupação e geração de renda em atividades que não envolvam o desmatamento é decisivo para "quebrar" os elos que sustentam a pobreza e o desmatamento na região [...].

Diniz (2017) assinala ainda, entre outros aspectos, o ecoturismo como um dos vetores de transformação dos recursos naturais da Amazônia.

Estudos realizados pelo IDEFLOR-Bio (2018), indicam que "[...] aproximadamente 28 famílias residem na unidade, as quais trabalham na extração do látex da seringueira, do urucum e do cacau, na pesca de subsistência e na exploração do açaí". A atividade extrativista do látex remonta ao tempo áureo de desenvolvimento socioeconômico que predominou na Amazônia entre os séculos XIX e XX, também conhecido como ciclo da borracha. Daí a área de localização do REVISMA ser conhecida, popularmente, como área da Pirelli, em virtude da predominância da atividade extrativista do látex, como fonte de geração de trabalho e renda para as comunidades locais (Figura 3).

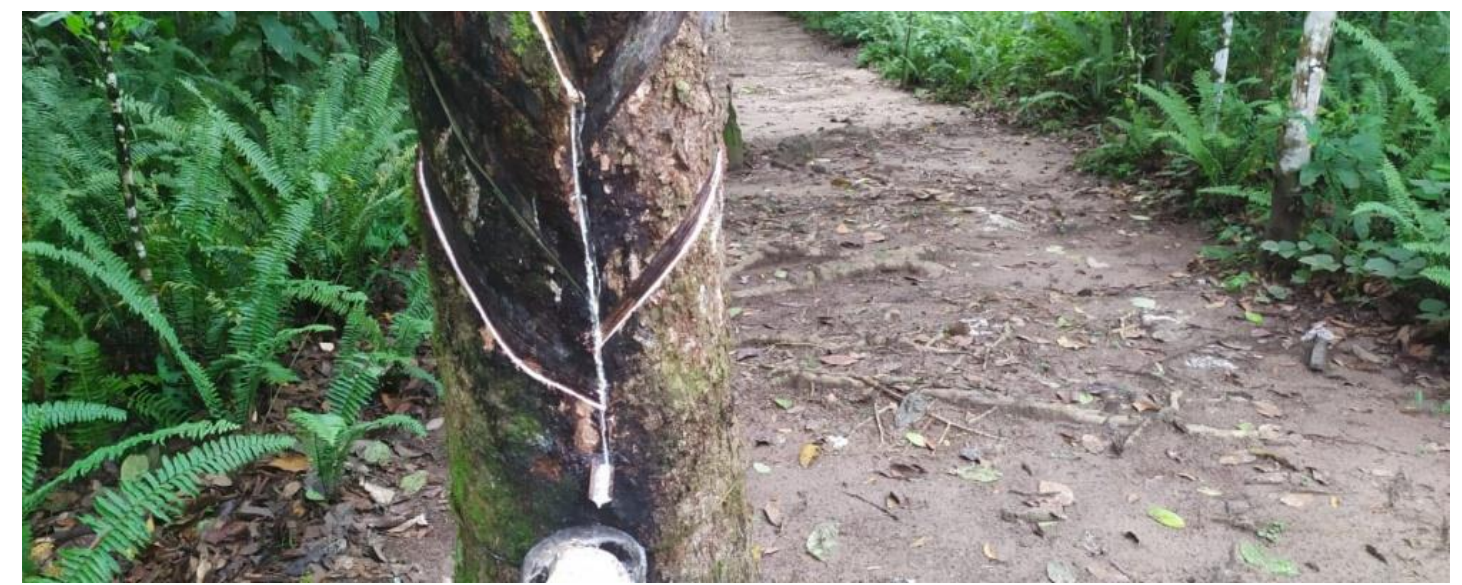

Figura 3: Processo de extração do látex

Figure 3: Latex extraction process

Fonte: Ideflor-Bio (2019).

Source: Ideflor-Bio (2019).

Em pesquisa realizada no REVISMA por Almeida, Bahia e Nelson (2016, p. 555-556), observa-se que a exploração dos recursos naturais é realizada de maneira sustentável: 
Para os moradores que já residem há várias gerações, nas comunidades ribeirinhas do REVIS, ao longo do rio Guamá, furos e igarapés, a situação fundiária é menos preocupante, pois, como populações tradicionais que são, utilizam, teoricamente, os recursos naturais de forma sustentável, e os seus objetivos vão ao encontro dos objetivos da criação da UC em área urbana, o extrativismo ainda é praticado pelas pessoas que moram ao longo do rio Guamá, nas áreas ribeirinhas.

A extração do látex da seringueira (Havea brasiliensis) ou da coleta de urucum (Bixa orellana) e cacau (Theobroma cação), plantas que foram cultivadas na área e que hoje existem na floresta, são fontes de obtenção de renda às comunidades. Segundo a SEMA (2009) a pesca também é praticada para subsistência da mesma forma como era há dez anos.

O açaí (Euterpe oleracea) é abundante na região e serve de alimento para os moradores, porém, também é alvo de invasores da área, que colhem o fruto e o palmito para a comercialização, prática não autorizada pelo órgão responsável pela UC, já que a existência do açaí contribui para a alimentação e reprodução da vida silvestre, objetivo principal da criação da Unidade de Conservação.

A continuidade da exploração dos recursos naturais pelas populações residentes deve ser um ponto a ser discutido e acertado para a minimização dos conflitos. Esses recursos podem ser utilizados sem que haja o seu esgotamento, se for feito de maneira sustentável e com o acompanhamento dos gestores das UC. Além disso, deve-se considerar a relação que os residentes já possuíam com a terra antes da criação da UC e da dependência dos recursos naturais para a sobrevivência.

Neste contexto, os aspectos socioeconômicos intrínsecos às relações sociais, em especial àquelas que se estabeleceram ao longo dos anos e que corroboraram, de maneira significativa para a conservação da natureza são importantes para a utilização dos recursos naturais como modo de subsistência das comunidades locais. Por outro lado, a legislação em vigor restringe o acesso de pessoas na UC de Proteção Integral. Esse é um desafio a ser estudado e interpretado com base na análise jurídica que considere o contexto atual na elaboração e aplicação dos instrumentos de gestão e administração do REVISMA. 


\section{Resultados e Discussão}

\section{Princípios do direito ambiental}

A Constituição da República Federativa do Brasil (CRFB) de 1988 dispõe no art. 225 sobre os direitos ambientais. Tais direitos são tratados como sendo um bem comum de todos ao meio ambiente ecologicamente equilibrado, impondo ao Poder Público e a coletividade a sua manutenção e conservação para as futuras gerações. Ao definir esse meio ambiente como essencial à qualidade de vida saudável, torna-se necessário a compreensão de vários princípios, que reunidos contribuem para uma visão holística da definição do meio ambiente.

O meio ambiente, enquanto direito coletivo, é essencial e precisa ser conservado para o bem de todos os seres terrestres. Assim, para melhor interpretação recorre-se aos teóricos em direito ambiental, com destaque para a definição de Trennenpohl (2010, p. 62-63), que enfatiza os princípios ambientais:

Princípio do Direito Humano Fundamental - considera o meio ambiente como uma extensão do direito à vida;

Princípio da Prevenção e da Precaução - visam evitar o risco de uma atividade sabidamente danosa e seus efeitos nocivos ao meio ambiente;

Princípio do Equilíbrio - tem como característica básica a ponderação de valores quando da prática de algum evento que possa repercutir na esfera ambiental;

Princípio da Responsabilidade - busca responsabilizar as condutas e atividades consideradas lesivas ao meio ambiente, sujeitando os infratores, pessoas físicas e jurídicas, a sanções penais e administrativas, independentemente da obrigação de reparar os danos causados;

Princípio do Poluidor-pagador - tentativa de impor ao poluidor o pagamento ou a majoração dos valores de suas atividades em razão de um maior impacto ambiental;

Princípio do Desenvolvimento Sustentável - é aquele que busca atender aos anseios do presente tentando não comprometer a capacidade e o meio ambiente das gerações futuras;

Princípio do Limite - impõe uma série de limitações a direitos individuais, tais como restrições ao uso e gozo da propriedade, à liberdade de comércio, de indústria e outras iniciativas privadas, sujeitando-os a controle especial, mediante atos de licenciamento, de aprovação, de fiscalização e de imposição de sanções;

Princípio Democrático - assegura-se a participação do cidadão na proteção do meio ambiente.

Os princípios definidos por Trennenpohl (2010) reforçam os direitos assegurados pela CRFB (1988) ao evidenciar os limites que devem ser impostos ao poluidor-pagador, por exemplo. O princípio da responsabilidade 
corrobora a importância de um estudo prévio de impacto ambiental, exigência assegurada pela CRFB. Ressalte-se que após a promulgação da CRFB ocorrem uma profusão de estudos e normas sobre a questão ambiental demonstrando a importância teórica e prática do tema.

Considerando-se que a CRFB no art. 225 define os princípios ambientais, resguardando o direito de todos de usufruírem de um meio ambiente ecologicamente equilibrado, objetivando assegurar a qualidade de vida da coletividade, compreende-se que é de competência do Poder Público fazer a defesa e o controle para garantir o bem estar das presentes e futuras gerações.

Portanto, o artigo acima mencionado deu origem à criação e reformulação da legislação ambiental vigente. Isto ocorreu com o intuito de organizar, disciplinar e legislar sobre quaisquer atividades que possa alterar ou modificar e transformar o meio ambiente, tanto pelo lado negativo quanto pelo positivo, dentre esse arcabouço legal destaca-se a Lei do SNUC.

\section{Contexto histórico de criação dos refúgios de vida silvestre}

O Século XX foi palco do debate mundial sobre as questões ambientais, tendo como marco a Conferência das Nações Unidas sobre Meio Ambiente Humano (CNUMAH) em Estocolmo, no ano 1972. Desde aquele momento, estudos realizados pelas Organizações das Nações Unidas (ONU) assinalavam que era necessário e urgente tomar decisões de maneira globalizada para conter as transformações da natureza causadas pela conduta humana. Isso quando da exploração indiscriminada de recursos naturais renováveis e não renováveis pelas relações dos seres humanos com a natureza, juntamente com o modo de produção e comercialização de poluentes, formavam o eixo central desses encontros. Haja vista os efeitos difusos considerados altamente perigosos para o futuro da humanidade.

A concepção nova de meio ambiente globalizado vai influenciar diretamente no ordenamento jurídico brasileiro com a promulgação da CRFB em 1988, em especial quando dispõe no Capítulo VI, art. 225, que trata das questões sobre o meio ambiente. O Brasil, quando inserido neste contexto, apropria-se do debate criando fóruns permanentes de discussão sobre a temática ambiental. Entre esses, a Agenda 21, instituída em 2002, mas que teve seu início de construção com a Conferência das Nações Unidas sobre o Meio Ambiente e o Desenvolvimento (CNUMAD) realizada no Rio de Janeiro no ano de 1992, também conhecida como Rio 92.

O Capítulo VI, da CRFB de 1988, estabelece princípios e diretrizes que deram origem as leis diversas, nas três esferas do Poder, objetivando a regulamentação de seus dispositivos. Para Rodrigues (2013, p. 157):

A lei do Sistema Nacional de Unidade de Conservação ou simplesmente SNUC, como é apelidada - é um diploma da maior relevância para a proteção do meio ambiente. É 
claro que, como toda lei, tem suas falhas, mas as suas virtudes superam em muito os seus defeitos.

Por intermédio desta lei, o legislador, regulamentando os incisos I e III do $\S 1^{\circ}$ do art. 225 da CF/88, colocou um ponto final nos chamados "parques de papel": criados por decretos e resoluções, eram utilizados como instrumento de perseguição política. Não tinham, assim, nenhum comprometimento com os elementos ou atributos ambientais da área protegida; eram criados sem consulta da população local; não estabeleciam regimes especiais de uso e fruição; restringiam a propriedade sem qualquer contraditório ou eventual indenização ao proprietário.

A criação e a gestão de Unidades de Proteção Integral (UPI) encontram-se estabelecidas na Lei $n^{\circ}$ 9.985/2000, que cria o SNUC, com objetivo de impor limites para disciplinar o uso dos recursos naturais em áreas que se caracterizam pelo relevante interesse de proteger o meio ambiente.

Tal fato ocorre em virtude da fragilidade dos ecossistemas, que resguardam diversidade enorme de espécies da flora e da fauna aquática e terrestre. Assim, o SNUC define as UC:

Art. $2^{\circ}$ - Para os fins previstos nesta Lei, entende-se por:

I - unidade de conservação: espaço territorial e seus recursos naturais, incluindo as águas jurisdicionais, com características naturais relevantes, legalmente instituídas pelo Poder Público, com objetivos de conservação e limites definidos, sob regime especial de administração, ao qual se aplicam garantias adequadas de proteção.

As UC se dividem em duas categorias: as de Proteção Integral (PI) e as de Uso Sustentável (US); conforme disposto no art. $7^{\circ}$ do SNUC:

Art. $7^{\circ}$ As unidades de conservação integrantes do SNUC dividem-se em dois grupos, com características distintas:

I - Unidades de Proteção Integral;

II - Unidades de Uso Sustentável.

$\S 10$ O objetivo básico das Unidades de Proteção Integral é preservar a natureza, sendo admitido apenas o uso indireto dos seus recursos naturais, com exceção dos casos previstos nesta lei.

$\S 2^{\circ}$ o objetivo básico das Unidades de Uso Sustentável é compartilhar a conservação da natureza com 0 uso sustentável de parcela dos recursos naturais.

A categoria de Unidades de Uso Sustentável (UUS) é composta por Área de Proteção Ambiental (APA), Área de Relevante Interesse Ecológico 
(ARIE), Floresta Nacional (FLONA), Reserva Extrativista (RESEX), Reserva de Fauna (REFAU), Reserva de Desenvolvimento Sustentável (RDS) e Reserva Particular do Patrimônio Natural (RPPN). Ressalte-se que é nas UC de categoria UUS que são possibilitadas as atividades de visitação, contemplação da beleza natural, educação ambiental da população e, ainda, as de incentivo ao desenvolvimento da economia local como ocorre com o extrativismo, o ecoturismo e/ou turismo sustentável.

Diferentemente, as UPI têm seu acesso restrito à entrada e permanência de pessoas. O grupo das UPI é composto de Estação Ecológica (ESEC), Reserva Biológica (REBIO), Parque Nacional (PARNA), Monumento Natural (MONA), Refúgio de Vida Silvestre (REVIS). Este grupo de UPI busca evitar impactos ao meio ambiente, pois são, em grande parte, ecossistemas frágeis onde a biodiversidade existente se encontra ameaçada de extinção. Sendo assim, seu uso é autorizado somente para a realização de atividades na área da pesquisa científica. Esta UC visa conservar a natureza com base no controle do acesso e uso do espaço com visitação programada, voltada à realização de atividades de contemplação, objetivando sensibilizar as pessoas para a importância da preservação da biodiversidade, da sobrevivência e do bem-estar da coletividade e do meio ambiente natural (Figura 4).

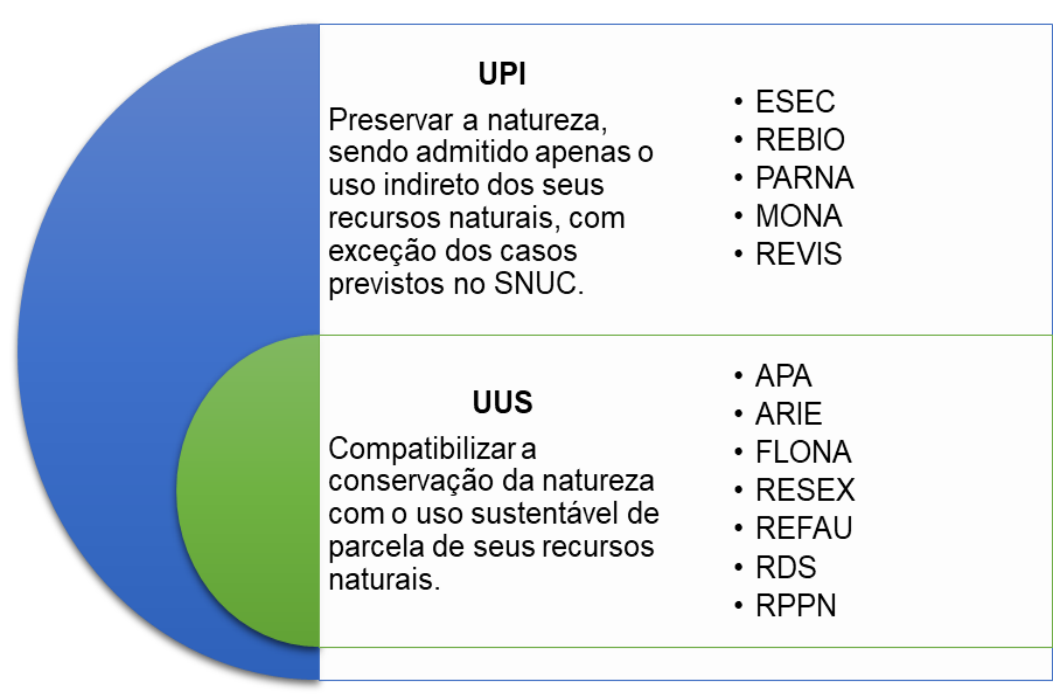

Figura 4: Categorias, objetivos e grupos de UC

Figure 4: Category, objectives and groups of the Conservation Area

Fonte: SNUC (2008), adaptado pelos autores (2020).

Source: SUNC (2008), adapted by the authors (2020).

Tais prerrogativas estão dispostas no art. $2^{\circ}$, inciso I, do SNUC, e vão ao encontro da definição de UC conforme explicitada e interpretada por Machado (2010, p. 860):

As unidades de conservação são espaços territoriais e seus recursos ambientais, incluindo as águas jurisdicionais, com características naturais relevantes, legalmente instituídos 
pelo Poder Público, com objetivos de conservação e limites definidos, sob regime especial de administração, ao qual se aplicam as garantias adequadas de proteção (art. $2^{\circ}$, I, da Lei 9.985/200).

As unidades de conservação inserem-se no conceito de área protegida, levando-se em conta a sua definição: "área definida geograficamente, que é destinada, ou regulamentada, e administrada para alcançar objetivos específicos de conservação",

A criação dos diversos tipos de unidades de conservação poderá comportar ou não "consulta pública". A lei analisada exclui da "consulta pública" a criação Estação Ecológica e da Reserva Biológica.

Neste sentido, as Unidades de Conservação da Natureza, de um modo geral, são consideradas instrumentos de gestão de Políticas Públicas de extrema importância no âmbito do Direito Ambiental.

Isto decorre porque sua criação é utilizada como uma maneira compensatória da exploração de recursos naturais renováveis e não renováveis inevitáveis ao desenvolvimento socioeconômico do país. Desse modo, se justifica a proteção e a conservação de áreas de relevante interesse naturais, como mecanismo de controlar a intervenção humana causadora de danos ou degradação do meio ambiente. Em virtude disso, torna-se necessário a elaboração de leis para delimitar e disciplinar quais áreas devem ser conservadas e quais as suas finalidades e importância para o equilíbrio do meio ambiente para as futuras gerações.

O objetivo da UPI REVIS encontra-se disposto no art. 13 do SNUC e para o entendimento de Antunes (2010, p. 582), são:

Os Refúgios de Vida Silvestre têm como objetivo proteger ambientes naturais onde se asseguram condições para a existência ou reprodução de espécies ou comunidades da flora local e da fauna residente ou migratória. Eles podem ser constituídos por áreas particulares, desde que compatíveis os objetivos da unidade com a utilização do solo e dos recursos naturais do local pelos proprietários. No caso da existência de incompatibilidades entre os objetivos da unidade de conservação e as atividades privadas ou, ainda, inexistindo a concordância do proprietário com as condições propostas pelo órgão responsável pela administração da unidade para a coexistência do Refúgio de Vida Silvestre com o uso da propriedade, a área deve ser desapropriada na forma da lei.

Ao observar a complexidade e a fragilidade existentes nas relações entre os seres humanos e o meio ambiente requer que o planejamento de ações seja fundamentado numa sequência constante de ação-reflexão-ação. 
Estas ações se não forem planejadas, podem causar desequilíbrio de ordem ecológico, social e econômico, causando sérios prejuízos a toda sociedade, em especial, as comunidades locais, que são as que mais sofrem as consequências provocadas pelos danos ambientais. Há de se considerar todos os instrumentos legais de prevenção para a proteção da natureza, para que todos os atores envolvidos no processo de utilização dos recursos naturais possam usufruir dos benefícios de maneira responsável. Isso é possível com o uso da ciência aplicada ao meio ambiente e dos instrumentos tecnológicos e legais, capazes de intervir para a melhoria dessas relações.

Tais níveis de complexidade das atividades são sequenciados por Vieira e Maimon (1993, p. 27-28), como:

No âmbito de uma reflexão exploratória sobre alternativas de ordenação e programação estratégica das ciências ambientais, o termo meio ambiente pode ser introduzido para designar um conjunto de componentes físicos-químicos e biológicos, associados a um conjunto de fatores sócioculturais, suscetíveis de afetar (direta-ou indiretamente, a curto, médio ou longo prazos) os seres vivos e as atividades humanas na ecosfera. Segundo esta acepção do termo, o campo integrado de pesquisas sobre o meio ambiente abrangeria 0 conjunto de transformações da ecosferaentendida como um sistema aberto complexo e hierarquizado-capazes de influenciar a manutenção das précondições de sobrevivência da espécie humana numa relação de co-evolução com outras formas de vida. Nesse sentido, cabe também ressaltar que essas transformações incluem uma dinâmica interativa altamente complexa de fatores bio-físicos e antropológicos.

A preocupação com o aprimoramento dos instrumentos de gestão e sua aplicabilidade no desenvolvimento das ações deve ter como ponto de partida a visão holística da problemática que envolve as comunidades locais.

Investir no engajamento das comunidades locais em prol da atividade a ser desenvolvida proporciona um mecanismo de gestão participativa fundamentada no comprometimento de todos os atores no que diz respeito à conservação da natureza. Tal estratégia possibilita também o acesso aos benefícios socioeconômicos por ela gerados, uma vez que o uso racional dos recursos ambientais está diretamente relacionado ao equilíbrio ecológico onde ocorrem. Nesse sentido, em conformidade com estudos de Leff (2007, p. 299):

A racionalidade ambiental promove estratégias para uma economia descentralizada, fundada no ordenamento ecológico do território e na gestão participativa da população sobre os recursos ambientais, estabelecendo novos equilíbrios regionais e redefinindo a capacidade de suporte 
físico de cada região ao crescimento populacional. Isto requer a articulação intersetorial das políticas populacionais com as políticas econômicas, científicas e tecnológicas, que permitam desenvolver o potencial ecológico para satisfazer as necessidades básicas de uma população crescente. Isto expõe a necessidade de articular processos de natureza diversa e diferentes escalas espaciais e temporais.

É com essa perspectiva que se pretende analisar a gestão e a administração da UPI REVISMA, observando-se a aplicação dos dispositivos legais em conformidade com a legislação ambiental vigente, e o modo de elaboração do Plano de Manejo do REVIS junto às comunidades existentes nessa grande área de extensão urbana.

\section{Das Populações Locais}

A delimitação da área juntamente com o uso dos recursos naturais são fatores que precisam encontrar-se bem definidos no Plano de Manejo para evitar a incidência de impactos socioambientais negativos. Esses fatores seriam prejudiciais ao controle e ao gerenciamento de atividades de proteção, haja vista que o REVISMA está localizado numa região metropolitana. Tal questão possibilita inferir que esta área está propícia a sofrer pressão da urbanização provocada tanto pela ocupação ordenada, proveniente da expansão imobiliária, quanto pela ocupação desordenada de terras públicas.

Em consonância com afirmações de Trennenpohl (2010, p. 243), o aparato legal já prediz o uso dos recursos naturais, senão veja-se:

A lei prevê o uso direto, indireto e sustentável dos recursos ambientais. Entende-se por uso direto aquele que envolve coleta e uso dos recursos naturais. $O$ uso indireto é aquele que não envolve consumo, coleta, dano ou destruição dos recursos naturais.

Quanto ao tratamento das comunidades residentes na área da UPI, deveria acontecer conforme dispõe o SNUC:

Art. 42. As populações tradicionais residentes em unidades de conservação nas quais sua permanência não seja permitida serão indenizadas ou compensadas pelas benfeitorias existentes e devidamente realocadas pelo Poder Público, em local e condições acordados entre as partes.

§ 1으 Poder Público, por meio do órgão competente, priorizará o reassentamento das populações tradicionais a serem realocadas. 


\begin{abstract}
$\S 2$ - Até que seja possível efetuar o reassentamento de que trata este artigo, serão estabelecidas normas e ações específicas destinadas a compatibilizar a presença das populações tradicionais residentes com os objetivos da unidade, sem prejuízo dos modos de vida, das fontes de subsistência e dos locais de moradia destas populações, assegurando-se a sua participação na elaboração das referidas normas e ações.
\end{abstract}

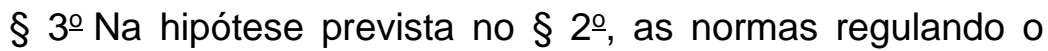
prazo de permanência e suas condições serão estabelecidas em regulamento.

Este é um ponto bastante polêmico que ocorre no REVISMA, pois estudos apontam a existência de 28 (vinte e oito) famílias residentes dentro da área de extensão.

O SNUC define que as famílias sejam indenizadas ou compensadas com benfeitorias, sendo o reassentamento priorizado pelo Poder Público. Nesse sentido, observa-se que o direito público se impõe ao direito individual ou privado com a finalidade de garantir que a política de proteção da natureza tenha, como pilar de sustentação, os princípios ambientais com o intuito de promover o bem-estar da sociedade.

As populações tradicionais residentes nessas áreas possuem um grande potencial de interação com a natureza e o estilo de vida voltado para a subsistência. Essa integração produz, através do senso comum, uma gama de conhecimento que é repassado de geração em geração e é externalizado nos costumes que se refletem nas diferentes maneiras de expressão cultural. A retirada das pessoas dos seus ambientes naturais, fundamentada no discurso oficial de proteger a natureza contra a ação humana, nos remete a visão do paraíso, o mito da natureza intocada.

Em estudo bastante referenciado sobre essa questão, Diegues (1994, p. 51) afirma que:

A concepção de áreas protegidas enquanto natureza selvagem parece ser um desses neo-mitos. Nela parece se operar uma simbiose entre o pensamento racional e o mitológico. Nesse conjunto de representações sobre 0 mundo natural intocado e intocável existem elementos claros que reportam ao pensamento empírico-racional, como a existência de funções ecológicas e sociais da natureza selvagem (o conceito de biodiversidade, por exemplo), dos processos ecológicos do ecossistema (recreação e elevo para as populações urbanas). De outro lado, existem nesse neo-mito elementos míticos claros que reportam à ideia do paraíso perdido, da beleza primitiva da natureza anterior à intervenção humana, da exuberância do mundo natural que leva o homem urbanizado a apreciar o belo, o harmonioso, a paz interior proveniente da admiração da paisagem intocada. 
Entende-se que não basta retirar as populações tradicionais ou não das áreas onde vivem há décadas, mas precisa antes de qualquer coisa, promover sua inclusão e readequação à realidade nova para que sejam assegurados os direitos, no que concerne à relação com a natureza e às manifestações culturais.

Sobre a lógica da apropriação dos territórios e o uso dos recursos naturais por ocupações humanas no estado do Pará, Simonian, Baptista, Pinto e Silva (2015, p. 485-486) argumentam que:

\begin{abstract}
Este modelo de apropriação e gestão dos recursos naturais na Amazônia [...], tem no estado do Pará o seu tipo mais puro de efetivação. De fato, esta unidade federativa brasileira vivencia, até os dias atuais, processos de ocupação que vem impactando, sobremaneira, seus ecossistemas naturais e desestruturando formações sociais que se edificaram historicamente, a partir de uma racionalidade não necessariamente mercadológica. São tribos indígenas, extrativistas florestais, pescadores artesanais, remanescentes de quilombos, ribeirinhos e outros que desenvolvem práticas produtivas de baixo impacto ambiental (Silva, 2010), configurando-se como verdadeiros arquétipos para as alternativas ao modelo de desenvolvimento predatório dominante na atualidade.
\end{abstract}

Partindo desse princípio, entende-se que o reassentamento dessas populações tradicionais significa a perda de sua identidade cultural, com a negação de suas origens, história e cultura. Certamente que se essas áreas permaneceram conservadas, mesmo tendo pessoas residentes, é porque essas mesmas pessoas vêm contribuindo para sua proteção.

\title{
Análise jurídica sobre a implantação e a administração do REVISMA
}

A UPI REVIS, de acordo com o art. 13 do SNUC, "[...] tem como objetivo proteger ambientes naturais onde se asseguram condições para a existência ou reprodução de espécies ou comunidades da flora local e da fauna residente ou migratória". (BRASIL, 2008, p. 21). O REVISMA foi criado pelo Decreto no 2.211, de 20 de março de 2010, do Governo do Estado do Pará e, após estudos socioambientais e levantamento de dados quantitativos e qualitativos realizados na área, identificaram-se os recursos naturais, as relações entre os seres humanos e a natureza, a ameaça de extinção de espécies da fauna e da flora amazônica. Com base nesse estudo houve a necessidade de intervenção do Estado para proteger esses ecossistemas, tendo seu objetivo disposto no art. 1ํ do referido Decreto, que é o de proteger os recursos naturais para assegurar as condições necessárias de existência ou sobrevivência das espécies, em especial das ameaçadas de extinção. 
Tal intervenção se dá pela proteção de ambientes naturais utilizados como refúgios para reprodução de espécies ou comunidades da flora e da fauna residente e/ou migratória, ou seja, é necessário criar condições favoráveis à manutenção da vida silvestre. Sobre a importância desta intervenção Almeida, Bahia e Nelson (2016, p. 553-554) explicitam que:

Neste contexto, o REVISMA foi criado como forma de resguardar a proteção de populações das espécies presentes na Unidade de Conservação que fazem parte da lista de espécies ameaçadas no Estado do Pará, de modo a atender principalmente as conclusões e recomendações desse trabalho, que divulgou a lista de "Espécies Ameaçadas e Áreas Críticas para a Biodiversidade no Pará", divulgada em 2009, considerada a primeira lista vermelha da região amazônica, que identificou um total de 181 espécies ameaçadas, incluídas nas categorias criticamente em perigo (13 espécies), em perigo (47) e vulneráveis (121 espécies). O trabalho foi iniciado em 2008, em parceria entre o Museu Paraense Emílio Goeldi (MPEG), a Conservação Internacional $(\mathrm{Cl})$ e a Secretaria de Estado de Meio Ambiente (SEMA). Estas mesmas instituições foram responsáveis pelos trabalhos que resultaram na lista das espécies da flora e da fauna ameaçadas no Estado do Pará, homologada por meio da Resolução COEMA no 54, de 24/10/2007 que consideram que as listas de espécies ameaçadas de extinção são importantes instrumentos de gestão ambiental e de conservação da biodiversidade.

Quanto à relação observada entre os seres humanos e meio ambiente, 0 art. $1^{\circ}$ do Decreto supracitado dispõe que a visitação é permitida para a realização de atividades de lazer e recreação com contemplação da natureza, de ecoturismo, das pesquisas científicas, da educação e da interpretação ambiental, visando "contribuir para a manutenção dos serviços ambientais, bem como garantir os processos ecológicos naturais" (PARÁ, 2010, p. 2).

Para o SNUC, nos seus $\S 3^{\circ}$ e $\S 4^{\circ}$ do art. 13 , tanto a visitação pública como a pesquisa científica devem ser normatizadas pelo órgão responsável pelo REVIS, com as restrições estabelecidas no Plano de Manejo da Unidade. Destaca-se ainda no Decreto no 2.211/2010, art. 5o, que as áreas limites do REVISMA "[...] poderão ser utilizadas para fins de compensação de reserva legal na forma da legislação federal e estadual pertinente e nos termos do seu plano de manejo" (PARÁ, 2010, p. 3).

Nos artigos subsequentes, o Decreto determina a área de extensão do REVISMA e sua regulamentação, bem como das intervenções que devem ser realizadas nessas áreas para diminuir os impactos ambientais e sonoros nos trechos da Alça Viária, nos lotes de terra destinados à habitação pertencentes à Companhia de Habitação do Governo do Estado do Pará (COHAB). No art. 7ํㅡㄹ trata da administração e composição dos 
representantes do Conselho do Consultivo e o art. 8ํㅡ, atribui ao Comandogeral da Polícia Militar do Estado, em parceria com o Órgão Ambiental Gestor, a responsabilidade pela guarda e segurança, em especial de invasões na área do REVISMA.

O órgão competente para gestar e administrar o REVISMA é o IDEFLOR-Bio, vinculado ao Governo do Estado do Pará. Essa instituição dispõe de uma equipe bem reduzida para realizar as atividades administrativas e funcionamento dos conselhos consultivo de todas as Unidades da RMB. Apesar de o REVISMA ter sido criado no ano de 2010, somente no ano de 2016 foi iniciado o processo de elaboração do Plano de Manejo. Tal documento vem a ser o principal instrumento de gestão para traçar metas e estratégias legalmente cabíveis à UPI, que de acordo com o SNUC:

Art. 27 - As unidades de conservação devem dispor de um Plano de Manejo.

$\S 1$ ㅇ O Plano de Manejo deve abranger a área da unidade de conservação, sua zona de amortecimento e os corredores ecológicos, incluindo medidas com o fim de promover sua interação à vida econômica e social das comunidades vizinhas.

$\S$ 3ㅇ O Plano de Manejo de uma unidade de conservação deve ser elaborado no prazo de cinco anos a partir da data de sua criação.

Art. 28 - São proibidas, nas unidades de conservação, quaisquer alterações, atividades ou modalidades de utilização em desacordo com os seus objetivos, o seu Plano de Manejo e seus regulamentos.

Parágrafo único. Até que seja elaborado o Plano de Manejo, todas as atividades e obras desenvolvidas nas unidades de conservação de proteção integral devem se limitar àquelas destinadas a garantir a integridade dos recursos que a unidade objetiva proteger, assegurando-se às populações tradicionais porventura residentes na área as condições e os meios necessários para a satisfação de suas necessidades materiais, sociais e culturais.

A elaboração do Plano de Manejo teve início com o Processo Licitatório, na Modalidade Pregão Eletrônico no 012/2016, Processo Administrativo no 2016/15258, que deu origem ao Contrato no 33/2016, entre o IDEFLOR-Bio e o Instituto de Avaliação, datado de 25 de agosto de 2016.

A elaboração do referido Plano foi deliberada junto ao Conselho Consultivo com a utilização de metodologia de caráter participativo, que inclui técnicas de construção coletivas, isto é, por meio da realização de oficinas participativas junto às comunidades interessadas. Em conformidade com a legislação vigente, leia-se o SNUC, que dispõe o seguinte: 
Art. 29. Cada unidade de conservação do grupo de Proteção Integral disporá de um Conselho Consultivo, presidido pelo órgão responsável por sua administração e constituído por representantes de órgãos públicos, de organizações da sociedade civil, por proprietários de terras localizadas em Refúgio de Vida Silvestre ou Monumento Natural, quando for o caso, e, na hipótese prevista no $\S 2^{\circ}$ do art. 42 , das populações tradicionais residentes, conforme se dispuser em regulamento e no ato de criação da unidade.

A importância do controle social na gestão das UC reside, principalmente, nas tomadas de decisões de interesses da coletividade.

Tais conquistas se devem há décadas de debates sobre as questões ambientais cujos resultados, positivos ou negativos, atingem direta e/ou indiretamente as comunidades locais. É o que se depreende das afirmações realizadas por estudos de Naves (2017, p. 5):

A gestão das Unidades de Conservação é colegiada, participando, organizadamente, a sociedade, a Administração Pública e as populações das áreas diretamente vinculadas às unidades. Essa gestão compartilhada e plural se materializa em Conselhos Consultivos ou Deliberativos, que serão presididos pelo chefe da Unidade de Conservação, o qual designará os demais conselheiros indicados pelos setores a serem representados.

A gestão compartilhada entre a Administração Pública e a Sociedade Civil Organizada foi executada em conformidade com as exigências legais, que consiste na estruturação e funcionamento da UPI, definindo as áreas do entorno de acordo com as finalidades que foram asseguradas no Plano de Manejo.

Estas prerrogativas são caracterizadas por Machado (2010, p. 872) da seguinte maneira:

O Plano de Manejo é o documento técnico mediante o qual, com fundamento nos objetivos gerais de unidade de conservação se estabelece o seu zoneamento e as normas que devem residir o uso e o manejo dos recursos naturais, inclusive a implantação das estruturas físicas e necessárias à gestão da Unidade (art. 2ํㅡ, XVII da Lei 9.985/2000).

Todas as unidades de conservação "devem dispor de um Plano de Manejo" (art.27) e o plano "deve ser elaborado no prazo de cinco anos", a partir da criação da unidade de conservação. Passado esse prazo, os órgãos executores (art. 6o , III), como o Instituto Chico Mendes - e, se não tiverem personalidade jurídica, os próprios governos estaduais e municipais, poderão figurar como réus na Ação Civil Pública. 
Quanto ao prazo previsto em lei de cinco anos para a elaboração do Plano de Manejo, no caso do REVISMA, este não foi cumprido pelo IDEFLOR-Bio, já que a UPI foi criada no ano de 2010 e, somente seis anos após, foi instaurado processo licitatório para a contratação de empresa especializada responsável pela elaboração, sendo concluído no ano de 2018. Essa desobediência legal cometida pela Administração Pública acaba contribuindo para o atraso nas tomadas de decisões, em especial às medidas necessárias para a execução de políticas ambientais que venham garantir a proteção das espécies da fauna e da flora endêmicas e/ou migratórias existentes no REVISMA.

Assim sendo, o Plano de Manejo, juntamente com o Resumo Executivo do REVISMA foi aprovado pela Portaria no 683, publicada no Diário Oficial do Estado do Pará de no 33.644, de 21 de junho de 2018, dando origem ao denominado Plano de Gestão da Unidade de Conservação REVISMA. Espera-se que esse instrumento de gestão possa contribuir para o equilíbrio socioambiental da RMB, com a aplicabilidade dos recursos financeiros, conforme previsto na Lei do SNUC, artigos 35 e 36.

\section{O Plano de Gestão e o ecoturismo como possibilidade de desenvolvimento local}

O Plano de Gestão do REVISMA é o instrumento de planejamento legalmente instituído que define as diretrizes e os objetivos a serem alcançados pela administração, execução, monitoramento e avaliação das ações, atividades e tarefas realizadas na implantação e desenvolvimento do ecoturismo no REVISMA.

O potencial e as possibilidades de crescimento das atividades ecoturísticas no REVISMA criam certa expectativa em virtude de suas características peculiares e por se tratar de uma UPI que contém comunidades residentes dentro de sua área limítrofe. Isto diverge do conceito de UPI disposto no SNUC, porém no Plano de Gestão observa-se que ele adota a definição de uso público com base na concepção do Ministério do Meio ambiente (MMA). Esta concepção envolve tanto atividades de lazer, práticas esportivas e recreativas, e educacionais (científica e ambiental).

Neste contexto, o uso público dá-se com base na inserção do visitante e sua aproximação com o meio ambiente na expectativa de proporcionar a conservação dos recursos naturais e culturais. Tal concepção de uso público possibilita o advento da categoria de "usuários indiretos" das UPI explicitada no Plano de Gestão como os gestores, prestadores de serviços e visitantes (IDEFLOR-Bio, 2018). Assim, o uso público passa a ter a perspectiva de promover a conservação dos recursos naturais e gerar receita e renda para a população.

Esta perspectiva de uso público pode contribuir para a diminuição dos impactos negativos das atividades de turismo e o aumento da pressão exercida pelas populações vizinhas ao ambiente protegido (DIAS, 2008, p. 134). De qualquer maneira, como observa Nogueira (2011, p. 99), tanto nas UUS quanto UPI "[...] é possível e desejável o desenvolvimento de 
atividades de uso público do turismo[...]", desde que se obedeçam às restrições estabelecidas para as atividades de acordo com a categoria de UC.

No território amazônico, a perspectiva de mitigação dos impactos negativos é condição sine qua non e urgente, embora ainda incipientes nas prioridades governamentais. Sobre este fato, Ribeiro $(2018$, p. 148) afirma que:

A Amazônia, cuja riqueza se concentra na sua biodiversidade, tem sofrido intensa pressão antrópica, decorrente do crescimento econômico e da rápida elevação da população. Isso acabou por conduzir a uma degradação dos ecossistemas e à redução dramática da cobertura da região. Ora, as políticas públicas estatais não vem tomando a devida consideração que o ecoturismo pode ser mais um instrumento na contenção do desmatamento na Amazônia. Muito pelo contrário, as ações governamentais hoje imperantes caminham no sentido inverso.

O ecoturismo é um segmento do turismo que vem sendo estudado por instituições como a Organização Mundial do Turismo (OMT) e Organizações Não-Governamentais (ONG) como a World Wildlife Fund (WWF), entre outras. Além disso, tem tido o contributo de teóricos internacionais e nacionais como Ceballos-Lascuráin (1999), Swarbrooke, (2000), Neiman e Mendonça (2000), Pires (2002), que se debruçaram sobre o assunto e desvendaram o espectro bastante amplo do tema.

O ecoturismo tem como característica o uso sustentável dos recursos naturais e o comprometimento com o desenvolvimento local, em especial das populações tradicionais habitantes de áreas protegidas. Podese afirmar que a relação do ser humano como o meio ambiente, no ecoturismo, é intrínseca a preservação do patrimônio natural e históricocultural, bem como as relações sociais existentes que contribuem para a manutenção dos costumes locais, de respeito à cultura e ao meio ambiente.

Ressalte-se que a essência do ecoturismo é justamente o compromisso com as futuras gerações, com a conservação do ambiente natural e histórico-cultural, sobretudo com o desenvolvimento sustentável local. Portanto, ao se criar uma UC deve-se partir de um planejamento que contemple o amplo espectro da atividade de ecoturismo e os objetivos do território a ser conservado. Nessa perspectiva, o processo de planejamento passa a ter a característica de prospectar alternativas não somente para a conservação de ecossistemas ameaçados, mas como proposta de continuidade da existência humana.

O Plano de Gestão do REVISMA é considerado o principal instrumento de planejamento e destaca a grandeza da diversidade natural, cultural e histórica da Região Amazônica. São três os corredores ecológicos que abrangem o município de Belém, denominados de: Mosaico de Áreas Protegidas da Região Metropolitana de Belém; Área de Proteção Ambiental (APA) da llha do Combu; Parque Estadual do Utinga (PEUt) e o REVISMA. 
Observa-se que dentre essas áreas que compõem os corredores ecológicos, apenas o REVISMA se inclui na categoria de UPI.

Quanto às atividades com potencial para o desenvolvimento no REVISMA, o Plano de Gestão aponta o aumento do ecoturismo, a recreação, a educação ambiental e as pesquisas científicas:

[...] o REVIS Metrópole da Amazônia apresenta significativo potencial ecoturístico, de turismo educacional, turismo científico, turismo histórico-cultural, turismo de aventura e turismo de experiência (SEBRAE, 2015), com suas paisagens diversas e relevante importância sociocultural e ambiental. (IDEFLOR-Bio, 2018, p. 163).

O fato do REVISMA estar situado no mesmo corredor ecológico do Parque Estadual do Utinga (PEUt), torna-se um diferencial importante para 0 desenvolvimento das atividades de ecoturismo na área, já que o PEUt é dotado de infraestrutura física e de acessibilidade para o público visitante.

Para além dos aspectos de infraestrutura e acessibilidade, o ecoturismo já vem sendo desenvolvimento pelas comunidades tradicionais que habitam as margens dos rios com a realização de passeios para contemplação da natureza, da cultura e da história local. Agora, espera-se que o Plano de Gestão, como instrumento de planejamento, possa cumprir o seu papel e alavancar as atividades de ecoturismo e, assim, contribuir para o desenvolvimento local. Isso porque as atividades de ecoturismo, como citadas, já vêm sendo realizadas no REVISMA como é o caso do birdwatching (Figura 5).

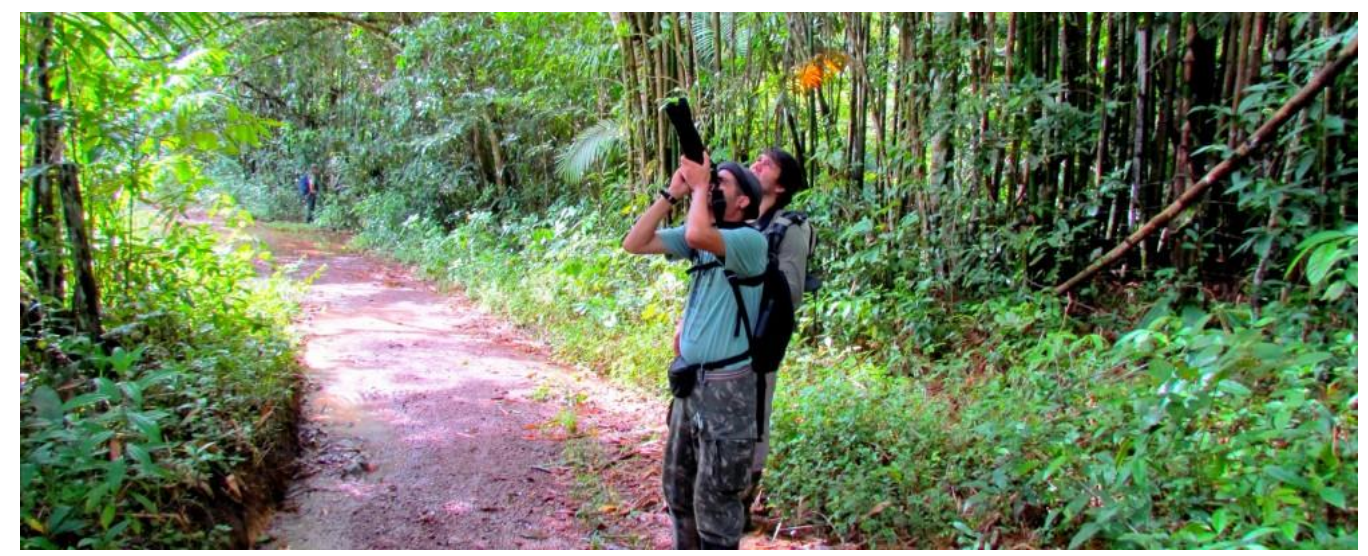

Figura 5: Atividade de birdwatching no REVISMA

Figure 5: Birdwatching activity in REVISMA

Fonte: Ideflor-Bio (2016).

Source: Ideflor-Bio (2016).

As atividades de lazer, esportivas, recreativas, educacionais, científicas e ambientais são citadas no Plano de Gestão em consonância com as orientações de Vallejo (2013), que prediz que: "o processo de aproximação entre visitante e o meio constitui importante instrumento de recursos naturais e culturais" (IDEFLOR-Bio, 2018, p. 151). Entretanto, o 
documento salienta que não existem levantamentos acerca do perfil do público visitante e que há um desconhecimento sobre a UC REVISMA por parte da população, e mesmo das pessoas residentes em seu entorno. Tal desconhecimento pode explicar a baixa demanda por emissão de autorizações para visitações como, por exemplo, de grupos esportistas e condutores ambientais. $\mathrm{E}$, ainda, o Plano registra que há visitantes não autorizados com práticas poluidoras e difíceis de serem coibidas pela insuficiência de equipe de fiscalização.

A incidência de práticas poluidoras foi corroborada quando da observação direta em uma comunidade quilombola localizada no interior do REVISMA e muitas vezes mencionadas pelos residentes. Naquela ocasião pode-se registrar a preocupação com depósitos de lixo a céu aberto por não residentes e as tentativas de invasão do território. As tentativas de invasão foram mencionadas como uma fragilidade do território ancestral frente ao adensamento urbano e a inércia das autoridades constituídas em protegê-los.

Além destes aspectos, a busca por proteger o território ancestral passava pelo reconhecimento da história da comunidade e o seu registro, pois não havia documentos escritos sobre o tema. Então, a transcrição das oralidades tornava-se necessária para reconfigurar os espaços e socializar as lutas por direitos travadas com o Estado e o seu apontamento para as futuras gerações. Digno de nota também é que o gênero feminino compõe a principal liderança e que estas mulheres estão concluindo cursos de graduação em nível superior.

A qualificação dos debates travados com esta comunidade quilombola foi ressaltada tanto nas falas do representante do Batalhão de Polícia Ambiental, quanto pelo Presidente do Conselho Gestor do REVISMA. Para estes, as conquistas até então efetivadas deveram-se ao protagonismo das quilombolas e o conhecimento destas sobre o território ancestral. Tal protagonismo também foi destacado pela representante e coordenadora do Plano de Gestão junto à empresa licitada.

Para a representante e coordenadora do Plano de Gestão, a qualificação dos debates ajudou o entendimento sobre as mais diversas problemáticas implicadas na administração e na gestão da UC REVISMA. Nesse aspecto, as reuniões com o Conselho Gestor também foram facilitadas pelo conhecimento amplo das conselheiras e conselheiros não somente sobre os territórios, mas também sobre questões jurídicas e administrativas que auxiliaram nas tomadas de decisões coletivas. Assim, o Plano de Gestão é o reflexo de decisões conjunturais que devem ser revisitadas e reformuladas com base na dinâmica dos processos históricos e biossocioculturais.

Portanto, espera-se que haja uma convergência entre o que está contido no Plano de Gestão do REVISMA, o que foi normatizado pela Lei do SNUC e os dispositivos do Direito Ambiental e da teoria e da prática do Ecoturismo. Que isto seja um diferencial para alavancar as atividades ecoturísticas, devido ao arcabouço natural, histórico e cultural conservados pelas populações tradicionais habitantes do REVISMA. 


\section{Considerações Finais}

Não cabem dúvidas de que os debates acerca da instituição de UC, na perspectiva de criação da categoria de manejo UPI, ainda necessitam ser realizados e aprofundados, principalmente com relação ao aspecto jurídico do tema. A presença de populações, tradicionais ou não, no interior das UC brasileira e amazônicas contribui para o acirramento das lutas em torno de direitos usurpados pelo Estado e para as críticas ao modelo importado de espaços naturais protegidos adotado por países, os mais distintos, e também pelo Estado brasileiro. A presença humana nesses territórios faz com que direitos constitucionalmente garantidos sejam impossibilitados de serem realizados e provocam lutas sociais permanentes.

Neste aspecto, a instituição do REVISMA encontra-se eivada de problemas de caráter socioeconômicos, ambientais, políticos e jurídicos desafiadores para uma UPI. A adoção de atividades do segmento de mercado do ecoturismo pode gerar novas possibilidades de conservação dos recursos naturais e, consequentemente, promover a sustentabilidade biossociocultural. Entretanto, deve-se atentar para a conjunção de objetivos entre a população residente, os prestadores de serviços terceirizados ou concessionários, os consumidores dos serviços e a pressão da ocupação humana, pois podem ampliar conflitos latentes.

As comunidades existentes nas áreas interiores ou de entorno do REVISMA lutam pela sobrevivência das atividades socioeconômicas e culturais ancestralmente realizadas e em pleno intercâmbio com os recursos naturais. As lutas pelo direito ao território ancestral fizeram com que movimentos da sociedade civil se organizassem para fazer frente às investidas das instituições estatais que solicitavam, com base nas normas legais, a sua retirada do território. Nesse aspecto, a Lei do SNUC é omissa e a profusão de normas que compõem o Direito Ambiental brasileiro contribui para a manutenção dos conflitos.

Apesar do Plano de Gestão do REVISMA não ter sido elaborado dentro do prazo previsto de cinco anos, uma vez que a UC REVISMA foi criada em 2010 e seu Plano de Gestão foi concluído no ano de 2018, o seu gerenciamento é primordial. Afirma-se isto em consequência da necessidade imperativa de se conter o avanço dos impactos ambientais negativos provocados pela ocupação urbana desordenada e a exploração dos recursos naturais, causadores da degradação ambiental e do aumento das desigualdades sociais.

Assim, é imprescindível a necessidade de estudos e pesquisa acerca do REVISMA e das problemáticas biossocioeconômicas e culturais decorrentes da sua instituição. Do ponto de vista jurídico, a criação do REVISMA, enquanto categoria de UPI, reforça a necessidade de revisão das categorias de manejo estabelecidas pelo SNUC. A presença de populações humanas no interior do REVISMA tem demonstrado que o uso indireto dos recursos naturais é extremamente danoso e torna invisível a relação ancestral dessas populações com os recursos naturais existentes no território protegido. 


\section{Referências}

ALMEIDA, M. P. S. R. Observação de aves no Refúgio de Vida Silvestre Metrópole da Amazônia: uma contribuição para a conservação ambiental da unidade e ao desenvolvimento turístico do estado do Pará. 2013. $134 \mathrm{f}$. Dissertação (Mestrado). Gestão de Áreas Protegidas da Amazônia. Instituto Nacional de Pesquisa da Amazônia. Manaus, AM, 2016.

ALMEIDA, M. P. S. R.; BAHIA, M. C.; NELSON. S. P. Observação de Aves no Refúgio de Vida Silvestre Metrópole da Amazônia: uma contribuição para a conservação ambiental da unidade e ao desenvolvimento turístico do Estado do Pará. Revista Brasileira de Ecoturismo, v. 9, n. 3, p. 544-574, 2016.

ANTUNES, P. B. Direito ambiental. $12^{\underline{a}}$ ed. Rio de Janeiro, RJ: Lumen Juris, 2010.

BABBIE, E. Métodos de pesquisa de survey. Belo Horizonte: UFMG, 1999. BRASIL. Constituição da República Federativa do Brasil. Brasília, DF: Senado Federal, 1988.

BRASIL. Lei n. 9.985, de 18 de julho de 2000. Institui o Sistema de Unidades de Conservação da Natureza. Brasília, DF: Senado Federal, 2000.

BRASIL. Unidades de Conservação da Natureza. Brasília: Senado Federal, Subsecretaria de Edições Técnicas, 2008. (Coleção Ambiental; v. 8).

CEBALLOS-LASCURÁIN, H. O ecoturismo como um fenômeno mundial. In: LINDENBERG, K.; HAWKINS, D. E. (Org.). Ecoturismo: um guia para planejamento e gestão. São Paulo: SENAC, 1999.

DIAS, R. Turismo sustentável e meio ambiente. São Paulo: Atlas, 2008.

DIEGUES, A. C. S. O Mito moderno da natureza intocada. São Paulo, SP: NUPAUB/USP, 1994.

DINIZ, M. B. Desmatamento e ausência de riqueza na Amazônia. Belém: Paka-Tatu, 2017.

IDEFLOR-BIO. Instituto de Desenvolvimento Florestal e da Biodiversidade do Estado do Pará. Refúgio de Vida Silvestre Metrópole da Amazônia. Disponível em: <http://ideflorbio.pa.gov.br/unidades-de-conservacao/regiaoadministrativa-de-belem/refugio-de-vida-silvestre-metropole-daamazonia/21>. Acesso em: 25 jun. 2018.

IDEFLOR-BIO. Instituto de Desenvolvimento Florestal e da Biodiversidade do Estado do Pará. Plano de Gestão da Unidade de Conservação Refúgio de Vida Silvestre Metrópole da Amazônia (REVIS). Brasília, DF: Contrato IA/Ideflor-Bio (n. 033/2016), 2018. 400 p.

IDEFLOR-BIO. Instituto de Desenvolvimento Florestal e da Biodiversidade do Estado do Pará. Portaria n. 683, de 21 de junho de 2018. Aprovação de Plano de Manejo e Resumo Executivo. Diário Oficial do Pará, n. 33644, de 26 de junho de 2018, p. 54.

IDEFLOR-BIO. Instituto de Desenvolvimento Florestal e da Biodiversidade do Estado do Pará. Resolução n. 01/2017. Promulga o Regimento Interno do Conselho Gestor do Refúgio de Vida Silvestre Metrópole da Amazônia. Diário Oficial do Pará, n. 33397, de 19 de junho de 2017, p. 29-30. 
IDEFLOR-BIO. Instituto de Desenvolvimento Florestal e da Biodiversidade do Estado do Pará. Cartilha temática: Plano de Gestão da Unidade de Conservação Refúgio de Vida Silvestre Metrópole da Amazônia (REVIS). Brasília, DF: Contrato IA/Ideflor-Bio (n. 033/2016 - etapa 7), 2018. 32 p.

IDEFLOR-BIO. Instituto de Desenvolvimento Florestal e da Biodiversidade do Estado do Pará. Resumo executivo: Plano de Gestão da Unidade de Conservação Refúgio de Vida Silvestre Metrópole da Amazônia (REVIS). Brasília, DF: Contrato IA/Ideflor-Bio (n. 033/2016 - etapa 7), 2018. 52 p.

LEFF, E. Saber ambiental: sustentabilidade, racionalidade, complexidade, poder. 5a ed. Petrópolis, RJ: Vozes, 2007.

MACHADO, P. A. L. Direito ambiental brasileiro. 18 ed. São Paulo, SP: Malheiros, 2010.

NAVES, S. C. Unidades de conservação: um limite ao direito de propriedade.

$<$ http://www.conteudojuridico.com.br/artigo,unidades-de-conservacao-umlimite-ao-direito-de-propriedade,44102.html>. Acesso em: 03 jan. 2017.

NEIMAN, Z.; MENDONÇA, R. Ecoturismo: discurso, desejo e realidade. Revista Turismo em Análise. São Paulo, 11(2): 98-110, nov. 2000. Disponível em: <https: www.revistas.usp.br> Acesso em: 20 mar. 2021.

NETO, O. C. O trabalho de campo como descoberta e criação. In: MINAYO, M. C. S. (Org.). Pesquisa social: teoria, método e criatividade. Petropólis, RJ: Vozes, 2002. p. 51-66.

NOGUEIRA, S. M. B. Planejamento do ecoturismo em unidades de conservação no Brasil. In: TELES, R. M. S. (Org.). Turismo e meio ambiente. Rio de Janeiro: Elsevier, 2011.

OLIVEIRA, S. L. Tratado de metodologia científica: projetos de pesquisas, TGI, TCC, monografias, dissertações e teses. São Paulo: Pioneira, 2002.

PARÁ. Decreto n. 2.211, de 30 de março de 2010. Cria o Refúgio de Vida Silvestre Metrópole da Amazônia nos municípios de Ananindeua, Benevides, Marituba e Santa Isabel do Pará. Diário Oficial do Pará, Suplemento, 01 de abril de $2010 . \quad$ Disponível em: <https://www.semas.pa.gov.br/legislacao/normas/view/447>. Acesso em: 27 abr. 2021.

PINTO, P. M.; SOUZA, J. A. A. Mapa de Iocalização do REVISMA. Sistemas de Coordenadas Geográficas SIRGAS 2000 UTM 22S, Base cartográfica BCIM-IBGE, 2018; Ideflor-Bio, 2019, Belém, PA: LAIG/UFPA, 2020.

PIRES, P. S. Dimensões do ecoturismo. São Paulo: SENAC, 2002.

SEVERINO, A. J. Metodologia do trabalho científico. $23^{\mathrm{a}}$ ed., $12^{\mathrm{a}}$ reimp. São Paulo: Cortez, 2007.

SIMONIAN, L. T. L.; BAPTISTA, E. R.; PINTO, P. M.; SILVA, J. B. Formação socioambiental do estado do Pará. In: SIMONIAN, L. T. L.; BAPTISTA, E. R. (Org.). Formação socioambiental da Amazônia. (Coleção Formação Regional da Amazônia, v. 3). Belém, PA: NAEA/UFPA, 2015. p. 393-525.

RIBEIRO, E. M. Ecoturismo na Amazônia: premissas para tomada de decisões sobre políticas de turismo sustentável no Amazonas. In: 
NASCIMENTO, E. P.; COSTA, H. A. (Org.). Turismo e sustentabilidade: verso e reverso. Rio de Janeiro: Garamond, 2018.

RODRIGUES, M. A. Direito ambiental esquematizado. São Paulo, SP: Saraiva, 2013.

SWARBROOKE, J. Turismo sustentável. São Paulo: ALEPH, 2000.

TRENNEPOHL, T. D. Manual de direito ambiental. $5^{\mathrm{a}}$ ed. São Paulo, SP: Saraiva, 2010.

VALLEJO, L. R. Uso público em áreas protegidas: atores, impactos, diretrizes de planejamento e gestão. Anais - Uso Público em Unidades de Conservação, Niterói, v. 1, n. 1, 2013.

VIEIRA, P. F.; MAIMON, D. As ciências sociais e a questão ambiental: rumo à interdisciplinaridade. Belém, PA: APED/UFPA, 1993.

\section{Agradecimentos}

À equipe técnica do IDEFLOR-Bio e aos membros do Conselho Gestor do REVISMA. À Comunidade Quilombola do Abacatal. À Faculdade de Belém (FABEL). À Universidade Federal do Pará (UFPA).

Rosa de Figueiredo Lavor: Fundação Papa João XXIII, Prefeitura Municipal de Belém, Belém, PA, Brasil.

E-mail: rosalavor@gmail.com

Link para o currículo Lattes: http://lattes.cnpq.br/3859677298809159

Luiz Antonio Gomes de Souza Monteiro de Brito: Centro Universitário do Pará, Belém, PA, Brasil.

E-mail: luizbrito_@hotmail.com

Link para o currículo Lattes: http://lattes.cnpq.br/2244189950353544

Fernando Gomes Favacho: Faculdades Ideal - FACI Wyden, Belém, PA, Brasil.

E-mail: fernandofavacho@gmail.com

Link para o currículo Lattes: http://lattes.cnpq.br/4908649031477514

Paulo Moreira Pinto: Universidade Federal do Pará, Belém, PA, Brasil.

E-mail: pmpinto@ufpa.br

Link para o currículo Lattes: http://lattes.cnpq.br/6876291957759425

Data de submissão: 15 de setembro de 2020

Data de recebimento de correções: 22 de dezembro de 2020

Data do aceite: 22 de dezembro de 2020

Avaliado anonimamente 